\title{
Politics of Syrian Refugee Public Policy 2015 - 2016: A Study of the Influence of the French National Party on European Parliament Member Votes
}

\author{
Elva Sagita Cindra ${ }^{1,}$, Vishnu Juwono ${ }^{2 *}$, \\ (elvacindra@gmail.com ${ }^{1}$, vjuwono@ui.ac.id ${ }^{2}$ ) \\ Faculty of Social and Political Science, Universitas Indonesia, $16424^{1}$, Depok, West Java, Indonesia \\ Faculty of Administrative Science, Universitas Indonesia, 16424², Depok, West Java, Indonesia
}

\begin{abstract}
In 2015 a crisis occurred in Europe because of the influx of millions of refugees from the Middle East and Africa, mainly from Syria. The EU, as a supranational institution responsible for this issue, sought to resolve the crisis by issuing policies. One of the European Union institutions in charge of policy is the European Parliament. Members of the European Parliament (MEPs) while in parliament are no longer representatives of national parties, but representatives of European political groups. Making use of behavioral patterns theory in the process of public policy and the network of actors, this paper seeks to prove that France's national party does have an influence on the European Parliament (EP) members in the Syrian refugee policy of the European Union 2015-2016. European political groups are not the sole determinants of the decision of the French MEPs because this policy is crucial. This influence is seen when national parties and European groups have different views on an issue.
\end{abstract}

Keywords: Influence of national party, European Parliament, Syrian refugee policy, European Union, European political group, French MEPS

\section{Introduction}

The European Union (EU) is a supranational organization composed of European countries. EU member states must comply with European law. When the EU has responsibility over a particular issue, the laws of member countries cannot be contrary to European law [1]. In policy-making there are three EU institutions in charge: the European Parliament (EP), the European Commission (EC), and the Council of the European Union (CEU). The European Commission has the authority to propose a policy, the European Parliament and the European Commission have the authority to adopt and amendment, but only the European Parliament can withhold a policy from being ratified [2].

The European Parliament began as the General Assembly which was a representative of the national parliaments and operated within the European Coal and Steel Community. EP could to introduce amendments, decide decisions on a policy, and veto the Council [3]. Members of the European Parliament (MEPs) are directly elected by citizens in June every five years [1]. EP is the only institution in the EU selected through direct elections. Once elected, MEPs do not stand as part of a national party but are part of European political groups. At that time political parties no longer had a role because at initially their duties were only to act as a bridge between legislators and voters [4]. 
By 2014, the European Parliament was comprised of 751 members, each selected from all twenty-eight EU member states [1]. The French MEPs comprise 74 people from three national parties with the most parliamentary members come from Front National, Les Republican and Parti Socialiste. This makes France one of the key actors in EU policies. So that France's alignment with EU countries in a policy becomes important.

Currently Europe is facing an unprecedented influx of refugees with about 1.2 million entering in 2015. Current refugees flows are mainly from Syria [5]. The entry of Syrian refugees in 2015 became a cross-border crisis, as some European countries were directly or indirectly affected. Unprecedented public attention to political events, as well as media attention to the experience and the dramatic picture of the arrival of refugees in the EU on the media put a heavy burden on EU institutions. The EU issued policies to resolve the dilemma of the Syrian refugee crisis [6].

In general, the European countries have different refugee and immigration policies. The EU seeks to integrate the migration and asylum policies system of member states within legal frameworks such as the Schengen Agreement and the European Common Asylum System [7]. In this case of Syrian refugees, the European Commission launched a series of initiatives calling for unity and solidarity among member states, seeking to coordinate responses at supranational levels [7]. European Commission President Jean-Claude Juncker has proposed a burden-sharing between members. However, this announcement was met with strong resistance.

France and Germany as the countries with the most MEPs reacted differently to the refugee crisis. Germany emphasized humanitarian attitudes and focused on asylum policies and the sharing of burdens with neighboring countries in relation to the distribution of refugees; while the war on terrorism was a major concern of the French. The French authorities implied that it would be very unwise to welcome the flow of refugees "with open arms" [8].

Clearly France had a different position from the European Commission on refugee policies in 2015. It was likely that French national parties would influence the votes of MEPs belonging to their party in this policy, considering previous studies on the influence of national parties on European parliamentarians from their party. According to Faas [9], MEPs have three main interests: re-election, position and policy with Re-selection as the most important goal, because without it, there will be no position (in legislative) or policy (influence). Finke [10] adds that voting behavior is not exclusively driven by ideology, but is strongly influenced by MEPs concerns about their chances of being reelected. National parties are in control of re-election.

Furthermore, Yuvaci [11] shows how national parties influence MEPs through examples of voting cases for Turkish accession in the EU. Yuvaci acknowledges the influence of European political groups but they do not have as much as the national parties. National parties have a major role in influencing the decisions of MEPs when the issues discussed are controversial, in the sense that they attract media and public attention. The same preference could be found among MEPs of the same national party. It was too early to conclude that the 
MEPs of European political groups were the sole decision makers in parliament in the Syrian refugee policy of the European Union 2015-2016.

The significance of this study is to fill the gaps of studies on the behavior of MEPs in decision-making and the influence of national parties on MEPs. The issue of Syrian refugees in 2015 itself was a national issue for every EU member state but no one has done any research on the policy. So far there has been no study of the influence of national parties focusing on MEPs from France even though France is the second country with the largest number of parliament members after Germany. Therefore this paper seeks to focus on the influence of the French national parties on the votes of members of the European Parliament (2014-2019) in the policy of Syrian refugees of the European Union 2015-2016.

\section{Theoretical Review}

\subsection{The Theory of Behavior Patterns in the Public Policy Process}

and

In the EP itself are three forms of decision making i.e. consultation, co-decision,

In consultation, power is concentrated in the hands of the Commission and the Council. The giving of opinions by Parliament is only symbolic. On the one hand, the EP perceives consultation as a process in which it is safe to encourage conflict and confrontation, as it will not be responsible for the policy outcomes. As a result, MEPs pay little attention to the issues discussed in the consultation procedures and therefore participate less actively [3].

Co-decision forces the Council to change its behavior to include the EP into its legislative practice. The result is a norm of consensual behavior that is comprehensive, both inter-institutional and intra-institutional. Increased informal negotiations, especially in the early stages, create different roles for MEPs. A large European party enjoys the tyranny of the majority. The difficulty in building a winning coalition also has an impact on policy outcomes, as this reduces the reporting space to maneuver and leads to centripetal policy results. The majority of complainants are from the center right of the political spectrum and from the larger group [3]. The consent procedure is a simple mechanism used primarily for the ratification of international agreements. The approval procedure is substantially different from the other two procedures because the EP does not formally have the capacity to change the contents of an agreement. EP can vote to receive or reject a text. But MEPs cannot change the direction of policy [3]

\subsection{Actor Network Theory}

The actor network is a network in which the nodes are actors and the edges represent the form of interaction between actors. Edges can represent friendship between individuals, but can also represent professional relationships, exchange of goods or money, communication patterns, romantic or sexual relationships, and other types of connections. Several measurements can be used to measure a network such as degree of centrality, eigenvector centrality, katz centrality, page rank, hubs and authorities, closeness centrality, betweenness centrality, and modularity. Everything is used depending on the network that is formed [12]. 
3 characteristics of the network of actors formed:

1. No groups, only group formations. Associating with one group or another is an ongoing process consisting of an uncertain, fragile, and ever-changing relationship. Actors are made to adjust themselves in a group/s - often in more than one [13].

2. Action depends on many actors. An actor is never alone in performing an action. Actions are made and distributed among other actors. If an actor is said to be a network actor, then there will be uncertainty about the origin of the action [13].

3. The object also has an agent: everything that changes circumstances and actions. There is an intermediary in making actors act called actants. An actor takes action; actants make moves [13].

The behavioral pattern theory in the public policy process explains how EP and MEPs behavior influenced by procedures in the public policy process. There are three procedures: consultation, co-decision, and consent that result in different behavior of MEPs; whereas the network theory of actors is about the relationship between actors in a network. This theory will be used to observe the communities and actions of French MEPs. The similarity between the two theories is that they both observe factors that affect the votes of MEPs.

\section{Research Method}

In this study, researchers used qualitative research methodology. The data used is primary data which is obtained by processing data of meetings, debates, and voting from official EU websites and interviews with resource persons. Secondary data is obtained from a literature study. Researchers will process the data using Gephi from the perspective of 74 MEPs (2014-2019) from France related to the Syrian refugee policy of the European Union 2015-2016.

Gephi is a software used for visualizing qualitative data that will generate relationships, sets, and networks. A network is a group or an interconnected node and edge system. Gephi is used to answer relationships, what people are connected in the same way, how big the community is, whether there is a dialogue or communication, who talks to whom, how information exchanges in the network are made, who is central and who is marginal in the network [14]. The reason researchers use Gephi because visualization tools have become a powerful component of progress in in various fields of science. In many cases, data is summarized as graphs or charts can help illustrate ideas clearly [15].

Data obtained from opinions, debates, speeches in sessions, written declarations, questions in parliament, resolutions, and reports of each member on the official website of the European Union. The three policies that will serve as case studies are the situation in the Mediterranean and the need for a holistic EU approach to migration, asylum: provisional measures in favor of Italy and Greece, and refugees: social inclusion and integration into the labor market. It should also be noted that there is no clear definition or distinction between refugees, asylum seekers, and immigrants in EU policies. The refugee policies made by the EU cover these three types of terms.

\section{Result and Discussion}


Three refugee policies were discussed in the European Union in 2015-2016: the situation in the Mediterranean and the need for a holistic EU approach to migration, asylum: provisional measures in favor of Italy and Greece, and refugees: social inclusion and integration into the labor market. The EU approach to migration discussed solidarity and burden sharing between EU member states and the need for a similar approach to migration issues.

In Parliament, the Council's proposal was then processed by a committee in charge of the civil liberties, justice, and home affairs. In the form of a co-decision, the Commission and the Council accepted the Parliament proposal unanimously. The last vote of the European Parliament was on April 12, 2016 with a turnout of 717 members. A total of 459 votes (64\%) were in favor, 206 votes (29\%) resisted and $52(7 \%)$ abstained [16]. All the ENF rejected the resolution. There were diverse opinions from EPP, unanimous acceptance from S \& D.

In asylum: provisional measures in favor of Italy and Greece spoke of the relocation of refugees in need of international protection in Italy and Greece. This legislative proposal itself is under the commission of civil liberties, justice, and home affairs with consultation procedures. The European Parliament adopted a proposal amendment with $470(72 \%)$ votes for, $131(20.1 \%)$ votes against, and $50(8 \%)$ abstained [17]. All of the ENF rejected the resolutions; there were diverse opinions among the EPP, as well as a unanimous acceptance from S \& D. However, the amendments to proposals from the EPs were rejected by the Council and the Commission because they were considered irrelevant.

Next, refugees: social inclusion and integration into the labor market discusses refugee access in the labor market. This policy has a co-decision procedure under the employment \& social affairs committee with Benifei as the Rapporteur. Voting took place on July 5, 2016 reaching the required number of votes of 338 for it to be legitimate. The European Parliament adopted the resolution with $486(69 \%)$ votes favour, $189(27 \%)$ votes against, and $28(4 \%)$ votes abstained from the total of 750 members [18]. Once again the Commission provided support to this resolution. There is a similar pattern in the voting results of MEPs from France. French MEPs have different opinions in the voting process. All of the ENF rejected the resolution. There were diverse opinions among the EPP, and unanimous acceptance from $\mathrm{S} \& \mathrm{D}$.

The voice of the French MEPs was processed using Gephi version 0.9.2 with a total of 61 nodes and 218 edges. 61 nodes consisted of 52 MEPs, 3 French national parties, 3 European political groups, and 3 preferences. 52 French MEPs came from three parties with the largest number of MEPs namely FN, LR, and PS. The French national parties consisted of FN, LR, and PS. 3 European political groups consisted of ENF, EPP, and S \& D. 3 sentiments consisted of favor, against, and abstain. While edges were the relationships formed between these nodes producing 218 edges. The details are as follows:

1. French MEPs indirectly connected with French national parties. The given weight is 1 if only members are involved, 2 if the board is involved, and 3 if the chair is involved.

2. French MEPs indirectly connected with European political groups. The given weight is 1 if only members are involved, 2 if the board is involved, and 3 if the chair is involved.

3. French national parties directly connected with French MEPs. The given weight is 1 .

4. European political groups directly connect with French MEPs. The given weight is 1 . 
5. French MEPs connected with preferences. The given weight is 3 if directly expressed and 1 if not.

6. French national parties connected with preferences. The given Weight is 3 if it is directly expressed and 1 if not.

7. European political groups connected with preferences. The given weight is 3 if there direct expression and 1 if not.

To help researchers clarify what is meant by influence, the researcher will measure it using modularity class and betweenness centrality. Modularity is used to measure the power of network division into modules (also called groups or communities). In order to find a community it is necessary to divide the network into communities whose nodes are closely connected, with nodes from other, less connected communities. Modularity is a measure of how well a network can be divided into smaller groups, or modules [12], and useful in finding community structures [12].

Networks with high modularity have solid connections between nodes in the module but the connections are rare between nodes in different modules. The modularity algorithm applied in Gephi looks for closer connected nodes compared to other networks. The colors of the interconnected nodes will show different communities and which networks are more closely connected to each other than to other networks [12].

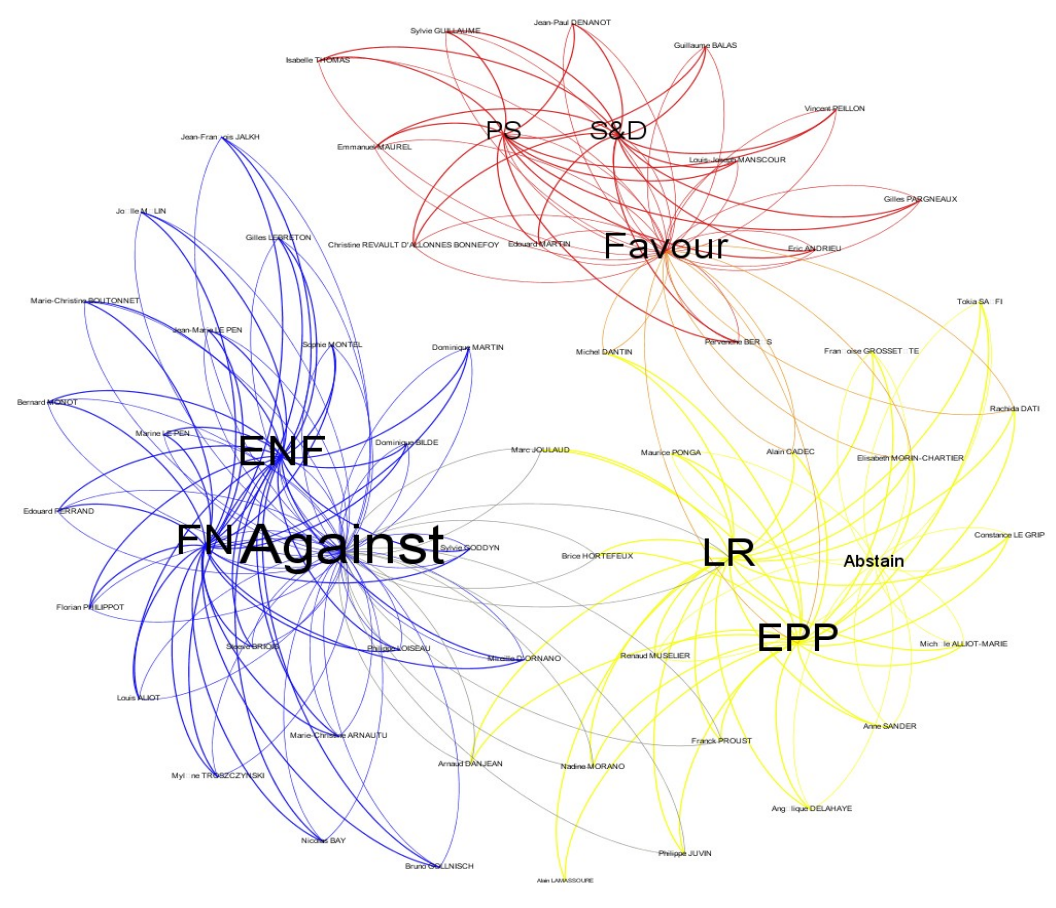

Figure 1. Modularity of the distribution of MEPs votes based on European political groups and national parties with fringterman reingold layout 
By looking at the Modularity Class Algorithm, it can be seen that there are three clustering preferences of choice from French MEPs. Modularity classes create three different groups or communities. PS and S \& D in red choose favour. FN and ENF in blue choose against. LR and EPP in yellow tend to choose abstain. Figure 1 shows that PS / S \& D and FN / ENF are not connected at all. This means that they do not have edges to connect to each other. Both are on opposite sides. Whereas LR / EPP have nodes and edges that connect to PS \& SD and FN / ENF; in other words there is no solidity in LR / EPP votes. To look deeply into the lack of solidity the within the LR / EPP members, the researcher will use betweenness centrality as a measurement.

Betweenness centrality shows which networks connect the most different communities simultaneously or the most influential nodes in networks that serve as intersections. From this measurement the most vulnerable network in each community that needs to be monitored further can be seen. Networks that are most important to a particular community can also be seen. Overall, the measurement of modularity allows vulnerable networks to be observed and provides an overview of the structure of the community [19]

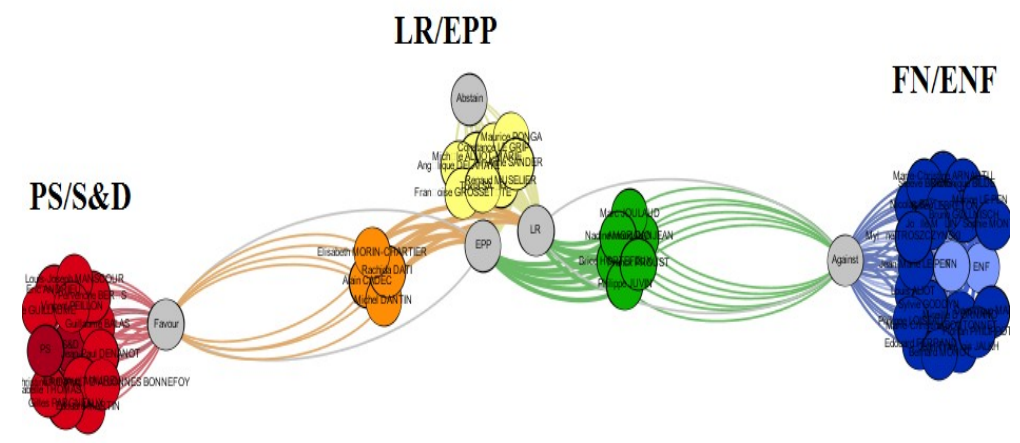

Figure 2. Betweenness centrality distribution of MEPs votes based on European political groups and national parties in the force atlas 2 layout.

Source: processed by researcher using Gephi

From Figure 2 we can see the color difference in LR / EPP. The sound distribution on PS / S \& D looks solid with red color between nodes. The same is seen in the nodes of FN / ENF with a uniform blue color. But in the LR / EPP nodes are formed three other communities with three different colors of orange, yellow, and green. To explain why this happens further then the researchers will see the relationship between European political groups and the French national party.

\subsection{Europe of Nations and Freedom (ENF) and Front National (FN)}


In accordance with the modularity and betweenness centrality it can be seen that the EP member nodes of FN and ENF are closely connected. The influence of the French national party on MEPs cannot be seen because FN and ENF have the same position in this policy. Both are against the policy of Syrian refugees of the EU in 2015-2016. As is known FN has seen immigration as a threat to national identity from the 1970 s onwards. The FN electoral manifesto states that immigrant 'integration' leads to the destruction of national identity [20].

The Front National (FN) is regarded as the most successful right-wing party in Western Europe. Based on traditional FN rhetoric, French society has been tarnished by foreign influences and oppressed by European integration and economic globalization. A nation should be made up of residents of states which have the same ethnic, cultural, religious and historical backgrounds. In practice, the FN position rejects foreigners and immigrants, who are often associated with unemployment, public insecurity, and welfare that should exclusively benefit the native French [21].

Europe of Nations and Freedom (ENF) was formed by Marine Le Pen in 2015. The ENF consists of extreme right deputies from France, Italy, Belgium, the Netherlands, Poland, Austria and England before it left the EU [22]. ENF bases their political alliances on the sovereignty of the state and its citizens. Opposition to the transfer of national sovereignty to a supranational body and / or European institution is one of the basic principles that unites members of the ENF. In addition ENF believes in the preservation of the identity of European citizens and countries, according to the specific characteristics of each country. The right to control and regulate immigration is a basic principle of ENF [23]. FN itself is the most dominant member in ENF.

According Teuku Zulkaryadi [24]:

Jean Marie Lepen is more radical, ultranationalistic, and chauvinistic than Marine Lepen. Marine Lepen is more moderate though still emphasizing on the same issues. FN itself is an eurosceptic party. Although it would be better to leave based on the rationale that there is more loss than benefits for France's joining the EU.

\subsection{European People's Party (EPP) dan The Republicans (LR)}

The voting results of the French MEPs originating from LR and EPP is divided into three voices: for, against, and abstain. Both LR and EPP themselves have different views on the policy of Syrian refugees of the EU in 2015-2016. LR with Sarkozy as leader are against the refugees. While EPP with Juncker as president hold an opposing position, were in favor.

From mid-2000 to early 2010 s, the election strategy of the LR as the center-right party was associated with the personality of Sarkozy. Sarkozy framed irregular immigration as a danger to European civilization and threatened to pull France out of the Schengen Treaty if border controls at the European level were not expanded [20]. Sarkozy said that selective immigration is an expression of French sovereignty. France like all other major democracies in the world has the right to choose which foreigners are allowed to live in France. In the same vein, Hortefeux stated that France has the right to choose who is wanted and who is acceptable within their borders [25]. 
This is very different from the EPP view. EPP President himself is Jean-Claude Juncker who is also President of the European Commission. As is known Juncker himself became the first voice from Europe who proposed a deal of burden-sharing. In May 2015, Juncker recommended the acceptance of 40,000 asylum seekers into EU countries based on wealth and population. This announcement was met with a strong resistance, and was regarded as an intrusion of European internal policy. In September 2015, Juncker again asked European countries to welcome 160,000 asylum seekers [6].

As a party EPP supports the principles of solidarity, sharing of burden and acceptance of refugees. The EPP defends Europe's core values of democracy, freedom, tolerance, human rights and the rule of law, as well as the need for a joint European solution and further rapid action to address the flow of refugees. In general, refugees should be supported and protected, and the capacity of EU countries to accept should be taken into account. The EPP wants the policy of Syrian refugees of the EU in 2015 - 2016 to be quickly adopted and implemented. Thus, it will speed up the procedure of asylum, encourage the proper functioning of return mechanisms and improve acceptance conditions for asylum seekers with support from the European Asylum Support Office (EASO), Frontex, and other EU institutions [26].

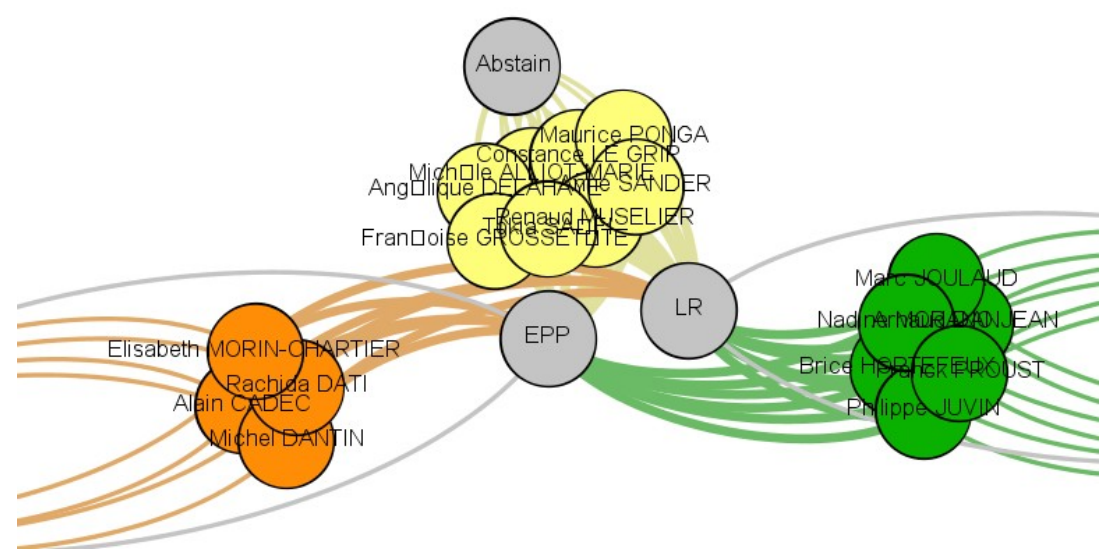

Figure 3 Betweenness centrality of LR and EPP

Source: processed by researcher using Gephi.

Figure 3 shows the influence of the French national parties when their position was different from the European political groups. EPP as a European political group has a solid vote in the refugee policy. The three colors in the LR / EPP network show which groups are vulnerable to influence by French national parties. In terms of position and distance between nodes, the orange color group will tend to choose according to the EPP position. While the group in green will tend to vote according to the French national parties. LR or EPP will contend over this group of abstaintees for influence of depending on a particular case depicted in yellow for. This alone shows the great influence of the LR party. Because with the MEPs themselves choosing to abstain, it can be considered not to follow the European political 
group. The number of MEPs who abstained and against is greater than those in favor, i.e. 14 to 4 .

\subsection{Progressive Alliance of Socialists and Democrats (S \& D) and Socialist Party (PS)}

The result of the voting of MEPs from S \& D and PS once again showed solidarity. This is because both have the same position regarding the policy of Syrian refugees of the EU in 2015-2016. Thus it cannot be seen as the direct influence of the French national parties themselves. The majority of PS members see these policies as humanitarian; solidarity among EU member states, and social integration should also be established to ensure the future lives of refugee in Europe.

PS as a French national party has a different approach to immigration from FN and LR. PS does not have an anti-multicultural view but believes that everyone has the right to be different. Hollande promised to break ties with Sarkozy's immigration and security policy [27]. Hollande concerned about the Syrian refugee crisis by 2015 announced that France would receive 24,000 refugees within the following two years. Some city mayors said they would work together to help ensure a smooth response to the refugees [28].

Hollande's decision to accept 24,000 refugees after the results of the survey showed that French sympathy for refugees is increasing can be seen as a decision to attract leftist voters ahead of the 2017 presidential elections (Briancon, 2015). Zulkaryadi said, "at the time of Hollande France itself was willing to accommodate a limited number refugees. There is no exact data but when it comes to burden sharing, France does not want to accommodate a higher number of refugees than Germany.' [24].

As is known S \& D has the same principle as PS. S \& D encourages a holistic European approach and policy on immigration and refugees. Solidarity, cooperation, and trust between EU member states to fulfill their responsibilities in accordance with the fundamental values of the EU are emphasized. The human rights-based approach to migration, which protects the rights of migrants and refugees in the migration policy and management, is the basic point of principle for S \& D which can never be compromised. Then it can be seen in the betweenness centerity of PS / S \& D that have a uniform color and only one big community is shown in red.

In terms of the Latour characteristic, in this case it can be seen that each member of EP is associated with at least two groups. MEPs here adjust to more than one group, as FN to ENF, LR to EPP, then PS to S \& D. MEPs on the one hand are trying to please European political groups that allocate resources in the EP; on the other hand they are trying to please the French national parties that control the election. In the original members of LR / EPP itself three other groups were found namely in favor, against, and abstain.

It can also be seen that an actor is never alone in taking action. Here the origin of the actions of MEPs can be controlled by European political groups or French national parties. Actions are made and distributed from one actor to another. But in the case of FN/ENF and PS / S \& D the origin of MEPs votes are not clear as both French national parties and European political groups share the same position. While in the case of LR / EPP the origin of the votes of MEPs is more apparent. Those who chose in favor are Michel DANTIN, Alain 
CADEC, Elisabeth MORIN-CHARTIER, and Rachida DATI who are closer to their European political group EPP. Those who voted against were Marc JOULAUD, Brice Hortelux, Nadine MORANO, Philippe JUVIN, Frank PROUST, Arnaud DANJEAN were closer to their national party LR. So it can be concluded that the influence of the French national parties is seen when European political groups and French national parties have different positions.

Lastly it is seen that the object also has an agent or everything that changes circumstances and actions. Intermediaries that make actors act are called actants. Actants in this case is the Syrian refugees policy of the European Union 2015-2016. The policy has led European political groups and French national parties to move and delegate their authority to actors. Actors, in this case MEPs, are expected to be able to bring the action or further the position of European political groups and French national parties and affect the actants directly. In other words because the actants is crucial then it can be the driving force of the actor. It is also the act that makes the difference between the actors involved as seen in the difference in votes between the French MEPs.

In Servent's theory it is true that the procedure in decision-making affects MEPs behavior. As seen in the refugee policy with the consultation procedure, MEPs take extreme positions by refusing one of the contents of relocation of refugees from Turkey. This is different when refugee policies have co-decision procedures. However, at the time of the vote, it turned out that in each procedure there was a similar pattern of voting from French MEPs. In all three voting policies, ENF / FN members voted entirely against, EPP / LR members' votes varied, and S \& D / PS members were all in favor. For reasons already set out in the analysis, in this case the procedure does not affect the votes of MEPs. The network of French MEPs that influenced them is between European political groups or national parties in accordance with Latour's theory.

\section{Conclusion}

The main argument of this paper is that it is premature to say that European political groups were the sole determinants of MEPs decisions in the Syrian refugee policy of 20152016. Nevertheless, there was an influence of French national parties on the French MEPs. In the analysis results, two things were found that should be emphasized. First, the policy of Syrian refugees of the EU in 2015-2016 was seen as crucial and influenced French politics so that the French national parties tried to influence the policy. Second, the influence of French national parties was seen when the national party had a different position from the European political groups.

In accordance with the Servent theory, differences in procedures do affect the way EP and MEPs behave; however, they are not dominant in this case. In terms of the Mediterranean situation and the need for a holistic EU approach to migration, the results of voting were valid and were successfully adopted. The procedure used was co-decision so that the EP had the power to pass a resolution on the Council and the Commission and the policy results are seen to be centripetal. The three institutions involved in policy making share a common view. The same thing also occurred with the refugees resolution proposal: social inclusion and integration into the labor market with the same procedure. 
Differences occurred in asylum: provisional measures in favor of Italy and Greece using consultation procedures. With consultation procedures the Council may adopt a legislative proposal after consultation with the EP without the obligation to follow the opinion of the EP. The Council rejected the proposed amendment of the EP as it was considered irrelevant. Later the Council adopted the decision immediately after the vote in the EP so that the vote of the MEPs was only symbolic. MEPs took extreme positions by refusing to directly relocate Syrian refugees from Turkey to member countries. In terms of the three policies discussed above, ENF / FN all rejected the resolution EPP / LR had varied votes, whereas S \& $\mathrm{D} / \mathrm{PS}$ gave their full support to the policies. The final procedure is the voting of a policy that connects us to the next theory.

In the modularity class three different communities were seen, namely ENF / FN, EPP / LR, and S \& D / PS. In betweenness centrality it appears that the ENF / FN were solid in voting to reject the policies. EPP / LR was divided into three communities that choose in favor, against, and abstain. S \& D / PS were solid in choosing in favor. The French MEPs had two communities: the European political parties and the French national parties.

The actions of French MEPs may be influenced by their European political groups or French national parties. Especially since the Syrian refugee policy of 2015-2016 is an important policy and a driving force for actors to act. In the case of ENF / FN and PS / S \& D there was no visible influence from the national parties because both have the same position. But EPP / LR that have different positions on the policy, the effect of the LR itself is seen. So it can be concluded French national parties do have an influence on their MEPs in the policy of Syrian refugees of the EU in 2015-2016.

\section{Acknowledgements}

The authors would like to thank all related actors to this research especially Mas Mahmud Syaltout and Mas Teuku Zulkaryadi.

\section{References}

\section{References}

[1] J. Pinder, The European Union: A Very Short Introduction, New York: Oxford University Press, 2001.

[2] EU Publications, How the European Union works: Your guide to the EU institutions, Luxembourg: European Union Publication Office, 2014.

[3] A. R. Servent, Institutional and Policy Change in the European Parliament Deciding on Freedom, Security and Justice, London: Palgrave Macmillan, 2015.

[4] W. T. Daniel, Career Behaviour and the European Parliament All Roads Lead through Brussels?, 
USA: Oxford University Press, 2015.

[5] N. Ostrand, "The Syrian Refugee Crisis: A Comparison of Responses by Germany, Sweden, the United Kingdom, and the United States," Journal on Migration and Human Security, vol. 3, no. 3, pp. 255-279, 2015.

[6] A. Grimmel and M. G. Susanne, Solidarity in the European Union A Fundamental Value in Crisis, Switzerland: Springer International Publishing, 2017.

[7] C. Morsut and I. K. Bjørn, "Crisis governance of the refugee and migrant influx into Europe in 2015: a tale of disintegration," Journal of European Integration, pp. 1-16, 2017.

[8] Think Tanks Tandem, "Terrorist Threats and Refugee Crisis: France and Germany Must Work Together to Rise to the Challenge," 15 December 2017. [Online]. Available: http://www.institutdelors.eu/.

[9] T. Faas, "National,institutional and party group pressures on MEPs and their consequences for party group cohesion in the European Parliament," European Journal of Political Research, vol. 41, p. 841-866, 2003.

[10] D. Finke, "Bicameralism in the European Union: parliamentary scrutiny as a tool for reinforcing party unity," West European Politics, vol. 40, no. 2, pp. 275-294, 2017.

[11] A. Yuvaci, "The Voting Behavior of the European Parliament Members on Turkish Accession: A Quantitative Analysis of a Special Status Amendment Vote on Turkey," Turkish Studies, vol. 14, no. 3, pp. 564-580, 2013.

[12] M. E. Newman, Networks: An Introduction, New York: Oxford University Press, 2010.

[13] B. Latour, Reassembling the social: An introduction to actor-network- theory, London: Oxford University Press, 2005

[14] V. Steeves and D. Sarah, "Network Diagrams for Qualitative Research," New York University Presentation, 2017.

[15] K.-H. Chu, W. Heather and V. Thomas, "Using Visualizations to Explore Network Dynamics," Journal of Social Structure, vol. 14, pp. 1-24, 2014.

[16] European Parliament, "Situation in the Mediterranean and need for a holistic EU approach to migration," European Parliament, 2016. [Online]. Available:

http://www.europarl.europa.eu/oeil/popups/ficheprocedure.do?lang=en\&reference=2015/2095. [Accessed 25 March 2018].

[17] European Parliament, "Provisional measures in the area of international protection for the benefit of Italy and Greece: relocation of applicants," 2016. [Online]. Available: http://www.europarl.europa.eu/oeil/popups/ficheprocedure.do?lang=en\&reference=2016/0089. 
[Accessed 2 April 2018].

[18] European Parliament, "Refugees: social inclusion and integration into the labour market," 2016. [Online]. Available: http://www.europarl.europa.eu/oeil/popups/ficheprocedure.do? lang=en\&reference $=2015 / 2321$. [Accessed 1 April 2018].

[19] V. D. Blondel, J. L. Guillaume, R. Lambiotte and E. Lefebvre, "Fast unfolding of communities in large networks," Journal of statistical mechanics: theory and experiment, vol. 10, 2008.

[20] J. Carvalho, "The impact of extreme-right parties on immigration policy in Italy and France in the early 2000s," Comparative European Politics, pp. 1-23, 2014.

[21] D. Stockemer, The Front National in France Continuity and Change Under Jean- Marie Le Pen and Marine Le Pen, Switzerland: Springer International Publishing, 2017.

[22] J. L. Abegnoli, "Far right MEPs form EU parliamentary group," 2015. [Online]. Available: https:// www.theparliamentmagazine.eu/articles/news/far-right-meps-form-eu-parliamentary-group. [Accessed 2018 March 23].

[23] ENF Official Page, "Philip Claeys Secrétaire Général Remarks," 2015. [Online]. Available: http:// www.enfgroup-ep.eu/about/. [Accessed 23 March 2018].

[24] T. Zulkaryadi, Interviewee, Interview. [Interview]. 25 April 2018.

[25] O. Ocak, Theorizing France's Ministry of Immigration: Borders, Population, and National Identity in Postcolonial Europe, A Dissertation Faculty of George Mason University, 2016.

[26] European People Party, "Protecting Lives and Controlling Migration to Europe Resolution adopted by the EPP Political Assembly," 2016. [Online]. Available: http://www.epp.eu/papers/protectinglives-and-controlling-migration-to-europe/. [Accessed 26 March 2018].

[27] C. Belmonte, A Comparative Analysis of The Immigration Policy in Italy, France, Norway and The Role of The European Union, Orlando: Thesis submitted at the University of Central Florida, 2012.

[28] P. Briancon, "Hollande's refugee policy divides French right: The French president's announcement caught his conservative opposition off guard," 2015. [Online]. Available: https://www.politico.eu/article/europe-refugee-crisis-hollande-refugee- policy-divides- frenchright-paris/. [Accessed 27 March 2018]. 